\title{
BIORESOURCES - AN ONLINE SCIENTIFIC JOURNAL DEVOTED TO LIGNOCELLULOSIC MATERIALS FOR NEW END USES AND NEW CAPABILITIES
}

\author{
M. A. Hubbe, ${ }^{a}$ and Lucian A. Lucia ${ }^{a}$ \\ In this inaugural issue, the Co-Editors of BioResources would like to \\ welcome you. In your role as a reader, we welcome you to download \\ scholarly articles and opinion pieces; this is an open-access journal, \\ providing a maximum of potential impact. BioResources will deal with \\ new and emerging uses of materials from lignocellulosic sources, \\ including wood and crop residues. We also would like to welcome you \\ as a prospective author. Our goal is to maintain very high standards of \\ peer-review, as well as providing a mix of scholarly research articles, \\ review articles, and editorials. By using an automated, online system of \\ review and publication, we hope to accelerate scientific discourse. Our \\ hope is to contribute to progress in the direction of a post-petroleum \\ economy, taking advantage of the renewable, biodegradable, and \\ relatively abundant nature of materials from lignocellulosic sources.
}

Keywords: Bioresources, Online journal, Lignocellulosic, Materials, Biomass

Contact information: a: Department of Wood and Paper Science, NC State University, Campus Box 8005, Raleigh, NC 27695-8005 USA; *Corresponding authors: hubbe@ncsu.edu; lucian.lucia@ncsu.edu

\section{THE NEED FOR A JOURNAL}

In our opinion, rapid and meaningful scientific and technological progress requires a high level of discourse. Suitable forums are needed in which scientists and engineers can exchange ideas and challenge others to work at increasingly high levels of innovation and sound scientific judgment. Discourse is the key, we believe, and that is why we have chosen to encourage editorial opinion pieces and scholarly review articles, in addition to research articles. We also believe that the peer-review process is centrally important as a scientific community grapples with the challenge of establishing new scientific knowledge and separating what can be proven from what cannot.

As Co-Editors, we were motivated to start the online, peer-reviewed publication BioResources in response to a growing urgency of efforts to grow a bio-based economy. Because cellulose and lignin rank as the first and second most abundant chemicals resulting from photosynthesis, it is clear that these materials, as well as byproducts of lignocellulosic materials, will play a central role in efforts to create such an economy.

While there exist high-quality research journals dealing with the science and technology of lignocellulosic materials and their uses, we intend BioResources to encompass a unique set of features. Emphasis will be placed on consequences of science that lead in the direction of sustainable technology. Though there is a need for work over a broad range of biomass issues, our focus will be mainly on lignocellulosic materials, such as wood, paper, and crop residues. Our target audience will include scientists and policy makers, some of whom have considerable experience within fields such as wood

Hubbe and Lucia (2006). "Editorial: Why BioResources?" BioResources 1(1): 1-2 
science, biomaterials, and papermaking science. Our target audience also will include people who are urgently looking to solve ecological problems or replace traditional manufacturing processes with more environmentally benign, green technologies.

\section{THE OPEN-ACCESS FORMAT}

As we contemplated publishing a journal in the field of lignocelluosic science, the Co-Editors of BioResources considered the following hallmarks of high-quality scientific journals:

- Relatively prompt, efficient process of peer-review

- Emphasis on content, rather than form

- Distribution as broadly as possible, i.e. high impact

In our opinion, a web-based format can meets these objectives in an ideal way. Because the entire process takes place online, using an automated system for reviewing articles and adding articles to the journal, it is possible to avoid various delays associated with printing and distribution. The process can be further streamlined, as we have chosen to do in the case of BioResources, by asking the authors to format articles in a "ready-toupload" condition. Though many journals are subscription-based, support from our university has made it possible for us to avoid the need for passwords or subscriptions. The open-access nature of BioResources is intended to maximize people's access to a body of scientific discourse that will have an impact on the future of all of us.

\section{HOW YOU CAN HELP}

Regardless of the manner in which a scientific journal is produced, most of the work is a labor of love. Much of it is volunteer labor, pure and simple. Scholarly journals depend on the generosity of scholars, working as volunteers, to judge the overall quality and intellectual soundness of submitted articles. Authors, too, often are required to work for the hope of glory and progress, rather than expecting significant monetary rewards for their work in preparing scholarly articles. The Co-Editors of BioResources, though we don't consider ourselves to be volunteers, are likewise embarking on this venture as an added part of our work. We will be using advances in software, where we can, to streamline the process of reviewing and posting articles, but we are committed to a doing a lot of hard work to make this journal a success.

You can help. The first way you can help is by contributing high quality research articles that fit within the scope of our journal. More information about the journal's scope appears elsewhere on the http://www.ncsu.edu/bioresources website. We are especially enthusiastic when we receive an article that conveys scientific or technical information in an engaging way, i.e. telling a story that will capture the attention of other readers. Because of the Internet, as well as some databases to which we subscribe, you can be sure that your article will be picked up by literature searches.

Other ways that you can help are by volunteering to review articles, or by nominating a highly qualified person to serve on our Editorial Board. Our e-mail addresses appear below the title to this editorial. Even if your only role is as a reader of articles in BioResources, we want to express our deep appreciation to you and our commitment to the research community that we serve. 